\title{
Recovery of Tetragonal Phase from Previously Transformed Y-TZP
}

\author{
Bruno Galvão Simba ${ }^{a, e *}$, Claudinei dos Santos ${ }^{a, b}$, Kurt Strecker ${ }^{c}$, Antonio Alves de Almeida Junior ${ }^{d,}$ \\ Gelson Luis Adabo \\ ${ }^{a}$ Universidade de São Paulo - USP, Escola de Engenharia de Lorena - EEL, Pólo Urbo-Industrial, s/n, \\ Gleba AI-6, CEP 12.600-000, Lorena, SP, Brazil \\ ${ }^{b}$ Universidade do Estado do Rio de Janeiro - UERJ, Faculdade de Tecnologia - FAT, Rod. Presidente \\ Dutra, km 298, CEP 27.537-000, Resende, RJ, Brazil \\ ${ }^{c}$ Universidade Federal de São João del-Rei - UFSJ, Campus Sto Antônio, Praça Frei Orlando, 170, \\ Centro, CEP 36.307-352, São João del-Rei, MG, Brazil \\ ${ }^{d}$ Universidade Estadual Paulista - UNESP, Faculdade de Odontologia de Araraquara - FOAr, R. \\ Humaitá, 1680, CEP 14.801-903, Araraquara, SP, Brazil \\ ${ }^{e}$ Universidade Estadual Paulista - UNESP, Faculdade de Engenharia de Guaratinguetá - FEG, Av. \\ Ariberto Pereira da Cunha, 333, Portal das Colinas, CEP 12.516-410 Guaratinguetá, SP, Brazil
}

Received: July 24, 2015; Revised: May 4, 2016; Accepted: May 23, 2016

\begin{abstract}
$\mathrm{ZrO}_{2}\left(\mathrm{Y}_{2} \mathrm{O}_{3}\right)$-based ceramics are widely used as biomaterials due to high fracture toughness, resulting from the tetragonal-monoclinic phase transformation in which the ceramic is submitted during crack propagation. In this context, studies involving the possibility of optimization of the tetragonal phase are important for the properties improvement of this ceramic. This study investigated the recovery of tetragonal phase from a previously transformed $\mathrm{ZrO}_{2}\left(3 \mathrm{~mol} \% \mathrm{Y}_{2} \mathrm{O}_{3}\right)$ ceramic. Zirconia samples were sintered at $1450{ }^{\circ} \mathrm{C}$, at $1530{ }^{\circ} \mathrm{C}-2 \mathrm{~h}$ and at $1600{ }^{\circ} \mathrm{C}-4 \mathrm{~h}$, in order to obtain materials with distinct microstructural features. The sintered samples were characterized by relative density, X-ray diffraction and scanning electron microscopy. Samples sintered at $1450{ }^{\circ} \mathrm{C}, 1530{ }^{\circ} \mathrm{C}-2 \mathrm{~h}$ and $1600{ }^{\circ} \mathrm{C}-4 \mathrm{~h}$, presented relative densities of $94.2,99.6$ and $99.7 \%$ with grains size averages of $0.28,0.49$ and 1.31 $\mu \mathrm{m}$, respectively. All samples were submitted to milling to induce the tetragonal $\rightarrow$ monoclinic phase transformation presenting 5, 50 and $65 \mathrm{vol} \%$ of monoclinic phase. Subsequently, heat treatments between $400{ }^{\circ} \mathrm{C}$ and $1200^{\circ} \mathrm{C}$ were conducted to retransform monoclinic in tetragonal phase. It has been found that the smaller the grain size after sintering, the lower the necessary annealing temperatures for fully recovering of tetragonal phase. Annealing temperatures of 950,1100 and $1200{ }^{\circ} \mathrm{C}$ were sufficient to recover almost fully the tetragonal phase.
\end{abstract}

Keywords: $\mathrm{ZrO}_{2}\left(\mathrm{Y}_{2} \mathrm{O}_{3}\right)$ ceramics, sintering, phase transformation, microstructure

\section{Introduction}

Yttria-stabilized tetragonal zirconia polycrystalline, Y-TZP, exhibits excellent mechanical properties due to the martensitic (tetragonal-monoclinic, $t \rightarrow \mathrm{m}$ ) phase transformation, accompanied by 3 to $5 \%$ volume change, which results in the well-known transformation toughening mechanism. In this way, it is possible to obtain a high strength and high toughness ceramic material ${ }^{1,2}$. Because of its excellent mechanical properties, biocompatibility and aesthetical appearance, Y-TZP has been widely used for fixed dental prostheses ${ }^{3}$.

During the fabrication of indirect zirconia-based restorations, small adjustments of the zirconia may be necessary to guarantee its perfect adaption to the patient's teeth. These adjustments by grinding may induce prematurely the $\mathrm{t} \rightarrow \mathrm{m}$ phase transformation, thus reducing its mechanical properties $^{4,5}$.

Mochales et al. ${ }^{4}$ demonstrated that tetragonal-monoclinic transformation occurs on the surface layers of Y-TZP during grinding. Furthermore, Borchers et al. ${ }^{5}$ evaluated

* e-mail: brgalvao@usp.br the influence of different environments and loads on the phase transformation and showed that up to $10 \%$ conversion occurs in Y-TZP sintered at $1500{ }^{\circ} \mathrm{C}$ and stored in distilled water at $80^{\circ} \mathrm{C}$ for $64 \mathrm{~h}$.

Denry et al. ${ }^{6}$ presented possible factors which leads to precocity on tetragonal-monoclinic phase transformation. Based on consideration that zirconia-based dental restorations consist of a zirconia core (3Y-TZP) layered with veneering porcelain to render clinically acceptable esthetics, they cite that veneering porcelain is sintered through a short baking cycle in the temperature range $800-900{ }^{\circ} \mathrm{C}$. Furthermore, occasionally, the restoration core can be adjusted by grinding and dental implant abutments also frequently require grinding before placement ${ }^{7-9}$. Another important factor related to tetragonal-monoclinic phase transformation is the hydrothermal degradation ${ }^{10}$.

The purpose of this study was to investigate the effect of heat treatment on the reversibility of $t-m$ transformation in $3 \mathrm{Y}-\mathrm{TZP}$, correlating the grain size of the sintered samples with this phenomenon. 


\section{Material and Methods}

\subsection{Processing and measurements}

Commercial pre-sintered $\mathrm{Y}-\mathrm{TZP}\left(\mathrm{ZrO}_{2}-3 \mathrm{~mol} \% \mathrm{Y}_{2} \mathrm{O}_{3}\right)$ blocks with $100 \mathrm{~mm}$ diameter and $10 \mathrm{~mm}$ height (ProtMat Advanced Materials - Brazil) were used in this study. 30 samples of $10 \times 10 \times 10 \mathrm{~mm}^{3}$ were prepared and sintered (heating and cooling rate of $10^{\circ} \mathrm{C} / \mathrm{min}$ ) under three different temperatures: $1450^{\circ} \mathrm{C}, 1530^{\circ} \mathrm{C}$ with an isothermal holding time of $2 \mathrm{~h}$ (sintering parameters recommended by the manufacturer to achieve better densification results) and at $1600{ }^{\circ} \mathrm{C}$ with isothermal of $4 \mathrm{~h}$.

The relative density of pre-sintered samples was evaluated by geometric method because of high open porosity of the samples. Relative density of the sintered samples was determined using the Archimedes principle. The microstructure of the sintered samples was analyzed by scanning electron microscopy, using a LEO 1450VP microscope. Polished surfaces were thermally etched at $1400^{\circ} \mathrm{C}$ for $20 \mathrm{~min}$, using a heating and cooling rate of $25^{\circ} \mathrm{C} / \mathrm{min}$. The average grain size of the samples was determined using image analyzer software, ImageJ, and measuring a grain population of more than 1000 grains.

\subsection{Crushing of the sintered samples}

In order to provide the largest possible amount of martensitic transformation, the sintered samples were crushed using agate-mortar, and sieved $(32 \mu \mathrm{m})$ to obtain a uniform particle size for different sintered samples.

\subsection{Thermal treatments}

The obtained powders were heat treated at temperatures of $400,600,800,900,950,1000,1100,1150$ and $1200^{\circ} \mathrm{C}$, for $15 \mathrm{~min}$, using a heating and cooling rate of $20^{\circ} \mathrm{C} / \mathrm{min}$.

\subsection{Phase analysis}

The phase composition of the pre-sintered blocks, sintered samples and crushed sintered samples, was analyzed by X-ray diffraction, Shimadzu XRD-6000, with CuKa radiation $(\lambda=1.5406 \AA) 2 \theta$ from $20^{\circ}$ to $50^{\circ}$ at an exposure time of 3 seconds per position and step size of $0.05^{\circ}$. The phases were identified by comparison of the peaks with the JCPDS files ${ }^{11}$.

The amount of monoclinic phase was determined from the $\mathrm{X}$-Ray powder pattern fitting technique, using model proposed by Toraya et al. ${ }^{12}$ for $\mathrm{ZrO}_{2}\left(\mathrm{Y}_{2} \mathrm{O}_{3}\right)$ samples: The monoclinic phase fraction $\left(\mathrm{X}_{\mathrm{M}}\right)$ was estimated in integrated intensity ration between $\left(\overline{\mathbf{I}}_{11}\right)_{\mathrm{M}}$ and (111) $)_{\mathrm{M} \text { monoclinic }}$ phase peaks, and the (101) $)_{\mathrm{T}}$ tetragonal peak, according to Equation (1).

$$
X_{M}=\frac{(\overline{1} 11)_{M}+(111)_{M}}{(\overline{1} 11)_{M}+(111)_{M}+(101)_{T}}
$$

The volumetric fraction $\left(V_{M}\right)$ of the monoclinic phase was then calculated by Equation (2) which is based on crystallographic correlations studied by Toraya et al. ${ }^{12}$.

$$
V_{M}=\frac{1.311 X_{M}}{1+0.311 X_{M}}
$$

The depth of the X-ray penetration into the sample surface was calculated considering the absorption by the material, given by Equations (3) and (4) ${ }^{13}$ :

$$
h=-\frac{\sin \theta}{2\left(\frac{\mu}{\rho}\right) \rho}\left[\ln \frac{I}{I_{0}}\right]
$$

with:

$$
\left(\frac{\mu}{\rho}\right)=w_{1}\left(\frac{\mu}{\rho}\right)_{1}+w_{2}\left(\frac{\mu}{\rho}\right)_{2}+\ldots
$$

Where:

$\left(\frac{\mu}{\rho}\right)=$ mass absorption coefficient $\left[\mathrm{cm}^{2} / \mathrm{g}\right](\mathrm{Zr}=$ $143 ; \mathrm{O}=11.5 ; \mathrm{Y}=134) ; \mathrm{h}=$ penetration depth $[\mu \mathrm{m}] ; \theta$ $=$ diffraction angle; $\mathrm{I}=$ intensity of the diffracted $\mathrm{X}$-ray beam; $I_{0}=$ intensity of $\mathrm{X}$-ray beam; $\mu=$ mass absorption; $\mathrm{w}=$ weight fraction of the element or component; $\rho=$ density $\left[\mathrm{g} / \mathrm{cm}^{3}\right]\left(\mathrm{Zr}=6.511, \mathrm{O}=1.354, \mathrm{Y}=4.472, \mathrm{ZrO}_{2}-3\right.$ $\left.\mathrm{mol} \% \mathrm{Y}_{2} \mathrm{O}_{3}=6.051\right)$.

\section{Results and Discussion}

\subsection{Pre-sintered block characterization}

The pre-sintered blocks present $80.2 \%$ of relative density aiming to facilitate the machining of dental parts. Figure 1 presents XRD pattern of the pre-sintered block. The result of the XRD analysis indicates the presence of tetragonal $\mathrm{ZrO}_{2}$ as major crystalline phase, while $12 \mathrm{vol} \%$ of monoclinic phase is observed.

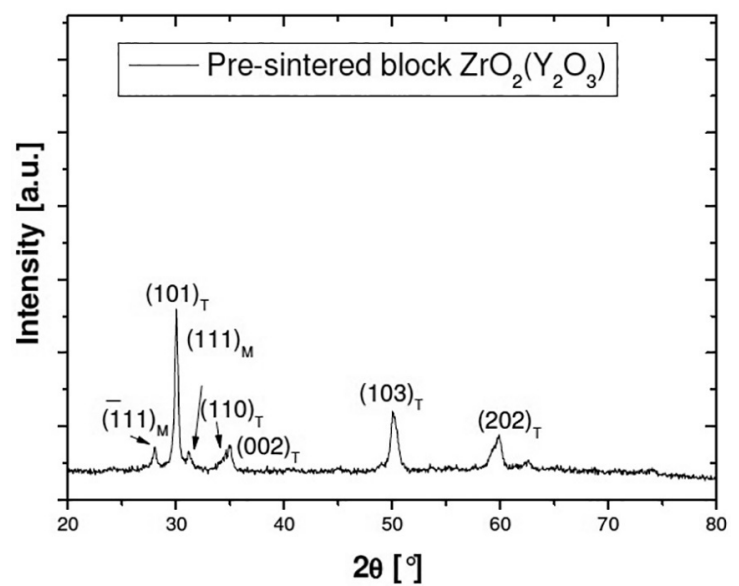

Figure 1: XRD pattern of the pre-sintered $\mathrm{ZrO}_{2}\left(\mathrm{Y}_{2} \mathrm{O}_{3}\right)$ block. 


\subsection{Characterization of the sintered samples}

Sintered samples exhibited relative density of $94.2 \pm$ $0.5 \%, 99.6 \pm 0.4 \%$ and $99.7 \pm 0.3 \%$ after sintering at $1450{ }^{\circ} \mathrm{C}$, $1530^{\circ} \mathrm{C}-2 \mathrm{~h}$ or $1600^{\circ} \mathrm{C}-4 \mathrm{~h}$, respectively. An increasing of densification is observed as function of sintering temperature increasing. Samples sintered at $1530^{\circ} \mathrm{C}-2 \mathrm{~h}$ and $1600{ }^{\circ} \mathrm{C}-4$ $\mathrm{h}$ lead to full densification, while samples sintered at 1450 ${ }^{\circ} \mathrm{C}$ present $94.2 \%$ of relative density, indicating no complete pores elimination in this sintering condition.

Figure 2 presents $\mathrm{X}$-ray diffraction of sintered samples. The results indicate only tetragonal $\mathrm{ZrO}_{2}$ as crystalline phase in all cases. The results indicate that, after sintering, monoclinic phase present in pre-sintered samples, Figure 1, was integrally transformed in tetragonal phase.

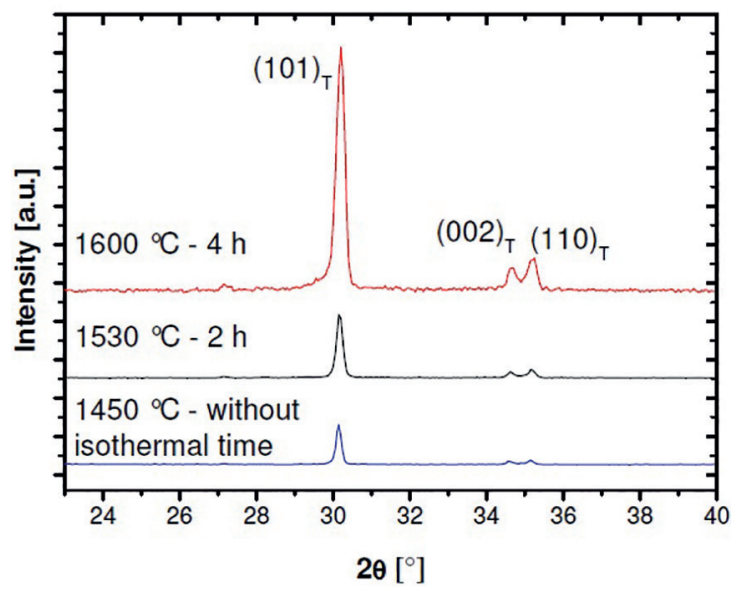

Figure 2: XRD patterns of the sintered samples.

Figure 3 shows SEM images of the sintered samples. Microstructural characterization indicated average grain sizes of $0.28 \pm 0.08,0.49 \pm 0.20$ and $1.31 \pm 0.67 \mu \mathrm{m}$ for samples sintered at $1450{ }^{\circ} \mathrm{C}, 1530{ }^{\circ} \mathrm{C}-2 \mathrm{~h}$ and at $1600{ }^{\circ} \mathrm{C}$ $-4 \mathrm{~h}$, respectively. As expected, considerable grain growth occurred with increasing sintering temperature and time.

\subsection{Characterization of the crushed samples}

Figure 4 presents representative XRD patterns of the crushed and heat-treated Y-TZP samples.

The fragmentation of the sintered samples allows simulating extreme conditions of phase transformation experienced by the material during application of mechanical stress. It can be observed that the increasing of heat treatment leads to a reduction of the monoclinic peak intensities in all sintering conditions experimented for zirconia samples.

Figure 5 shows the results of volume percentage of the monoclinic phase, determined by Equation (2), formed after crushing the samples (as milled) and after subsequent heat treatments from 400 up to $1200^{\circ} \mathrm{C}$.

The results of the phase analysis of sintered and crushed samples indicate that the amount of monoclinic phase formed depends on the grain size of the samples and, therefore, on the sintering temperature. Lower sintering temperatures result in a smaller grain size of tetragonal phase, making
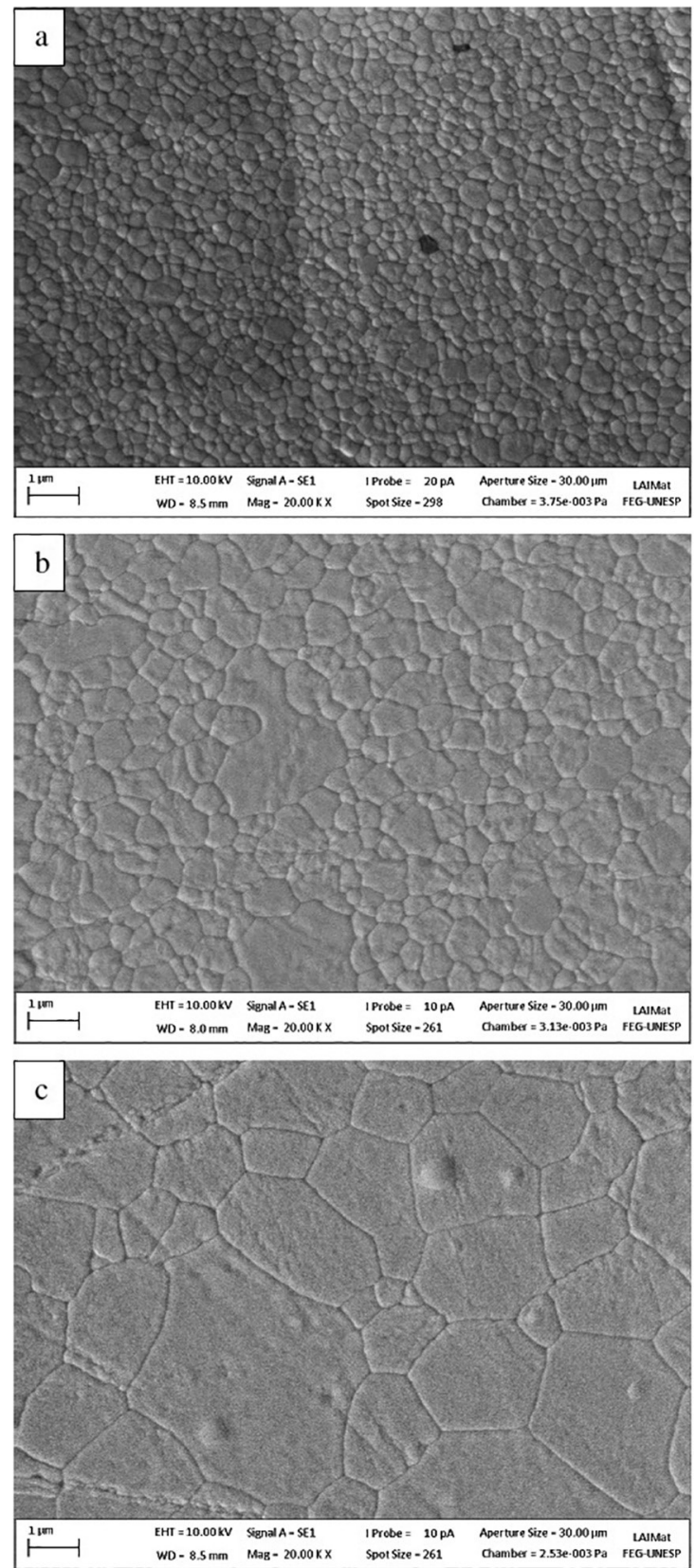

Figure 3: SEM micrographs showing different average grain size of samples sintered at: a) $\left.1450{ }^{\circ} \mathrm{C}, \mathrm{b}\right) 1530{ }^{\circ} \mathrm{C}-2 \mathrm{~h}$ and c) $1600{ }^{\circ} \mathrm{C}-4 \mathrm{~h}$.

the $t \rightarrow m$ transformation difficult, because the actual grain size is much smaller than the critical size for spontaneous transformation ${ }^{2}$.

The amount of recovery of tetragonal phase during the subsequent heat treatments also depends on the grain size achieved during sintering. While in the samples sintered at $1450{ }^{\circ} \mathrm{C}$ a full recovery of tetragonal phase is observed at temperatures as low as $950{ }^{\circ} \mathrm{C}$, the same for samples sintered at 1530 or $1600{ }^{\circ} \mathrm{C}$ is true only after treatments at 1100 and $1200^{\circ} \mathrm{C}$.

The percentages of monoclinic phase shown in Figure 5 are based on the percentage of grains analyzed by X-ray diffraction at the sample surface and their peak intensity. 

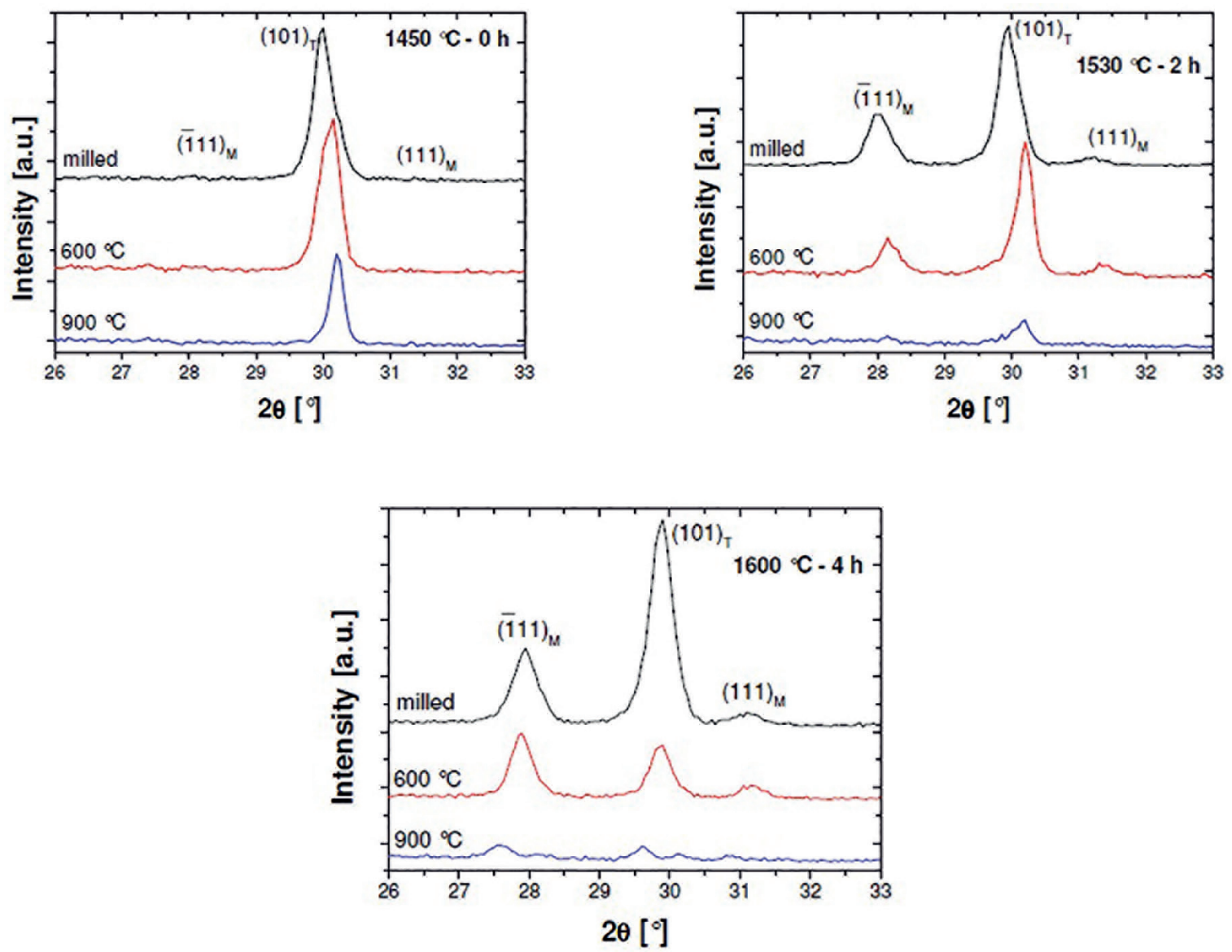

Figure 4: Representative XRD patterns of powder (crushed) samples before and after heat treatments.
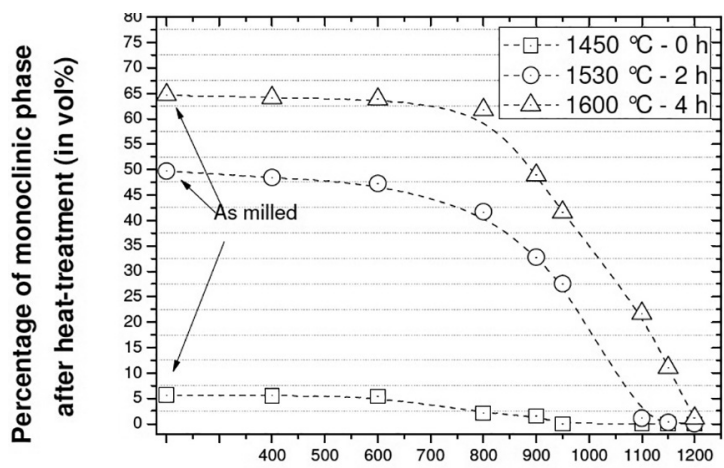

Temperature of Heat-treatment $\left[{ }^{\circ} \mathrm{C}\right]$

Figure 5. Amount of monoclinic phase formed after crushing the sintered samples (as milled) and after subsequent heat treatments.

Because the depth of penetration of X-rays, estimated to be in the order of $4.5 \mu \mathrm{m}$, it is reasonable to assume that the materials with larger grain sizes, as the samples sintered at $1600{ }^{\circ} \mathrm{C}-4 \mathrm{~h}(1.31 \mu \mathrm{m}$ grain size $)$ are much more influenced by the transformation at the fracture surface than samples with smaller grain sizes.

Therefore, volume fraction of monoclinic phase is a better representation of processing conditions experienced by the material within detection limit of about $4.5 \mu \mathrm{m}$ depth of the diffractometer. Analyzing this graph, the samples sintered at 1450 ${ }^{\circ} \mathrm{C}$ exhibit the lowest volumetric percentage transformed during crushing, about $6 \mathrm{vol} \%$, which corresponds to approximately one tenth of the amount transformed in the material sintered at $1600{ }^{\circ} \mathrm{C}$ for $4 \mathrm{~h}$. This difference is significant because a higher retention of tetragonal phase implies a higher life expectancy, especially when used in dental prostheses which are constantly under cyclic loading of mastication. A correlation between grain size and volume fraction of transformed monoclinic phase is showed in Figure 6.

It is possible to observe an increase of the amount of monoclinic phase with increasing grain size for different heat treatments used. In consequence, it becomes possible to predict the most appropriate heat treatment in function of the average grain size existing in the material to recover all or part of the tetragonal phase in zirconia. Based on these results, it is possible to propose heat treatments that minimize the transformation during processing. However, the results should be analyzed jointly with other properties evaluated, such as relative density, microstructural features, and especially mechanical properties of zirconia in order to optimize the performance of the ceramic material. Therefore, a special thermal treatment for each sintering temperature of zirconia after the grinding of zirconia-based restorations can be proposed to recover the tetragonal phase and improve their properties. 


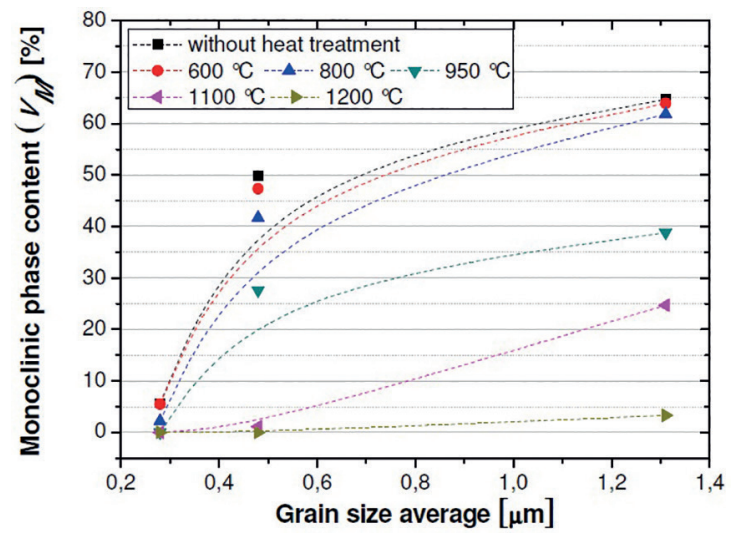

Figure 6: Volume fraction of monoclinic phase $\left(V_{M}\right)$ as function of grain size for different heat treatments applied.

For the development of this procedure, the thermal treatments for which the zirconia will be submitted by the application of the porcelain veneer should be known. Thus, the following items should be considered:

The sintered material may be subject to machining using diamond drills to optimize the adaptation to the patient's teeth, which will cause localized martensitic transformation.

In case of fixed partial prosthesis, mechanical stress on the prosthesis is critical and it is essential to optimize the percentage of tetragonal phase.

All zirconia used for dental prosthesis are covered by a feldspathic porcelain layer which allows to mimetic the color of a tooth. This porcelain layer is applied in 2 to 5 steps involving thermal treatments at about $950 \pm 50^{\circ} \mathrm{C}$.

\section{Conclusion}

The results indicated that sintering conditions of Y-TZP influenced tetragonal to monoclinic phase transformation due to the different microstructures. With the increasing sintering temperature and, therefore, the increasing grain size, the greater is the difficulty for the recovery of tetragonal phase. For a full recovery of the tetragonal for samples sintered at $1450{ }^{\circ} \mathrm{C}$ with an average grain size of $0.28 \mu \mathrm{m}$, heat treatment at $950{ }^{\circ} \mathrm{C}$ for $15 \mathrm{~min}$ is sufficient while heat treatments exceeding the martensitic transformation temperature of $1170{ }^{\circ} \mathrm{C}$ are required for samples sintered at $1600^{\circ} \mathrm{C}$ for $4 \mathrm{~h}$ with an average grain size of $1.31 \mu \mathrm{m}$.

\section{References}

1. Stevens R. An introduction to zirconia: Zirconia and zirconia ceramics. 2nd ed. Twickenham: Magnesium Elektron; 1986.

2. Piconi C, Maccauro G. Zirconia as a ceramic biomaterial. Biomaterials. 1999;20(1):1-25. PMID: 9916767 DOI: http:// dx.doi.org/10.1016/S0142-9612(98)00010-6

3. Rosenblum MA, Schulman A. A review of all-ceramic restorations. Journal of the American Dental Association. 1997;128(3):297307. DOI: http://dx.doi.org/10.14219/jada.archive.1997.0193

4. Mochales C, Maerten A, Rack A, Cloetens P, Mueller WD, Zaslansky P, et al. Monoclinic phase transformations of zirconiabased dental prostheses, induced by clinically practised surface manipulations. Acta Biomaterialia. 2011;7(7):2994-3002. DOI: http://dx.doi.org/10.1016/j.actbio.2011.04.007

5. Borchers L, Stiesch M, Bach FW, Buhl JC, Hübsch C, Kellner T, et al. Influence of hydrothermal and mechanical conditions on the strength of zirconia. Acta Biomaterialia. 2010;6(12):45474552. DOI: http://dx.doi.org/10.1016/j.actbio.2010.07.025

6. Denry IL, Peacock JJ, Holloway JA. Effect of heat treatment after accelerated aging on phase transformation in 3Y-TZP. Journal of Biomedical Materials Research Part B: Applied Biomaterials. 2010;93(1):236-243. DOI: http://dx.doi.org/10.1002/jbm.b.31580

7. Guazzato M, Quach L, Albakry M, Swain MV. Influence of surface and heat treatments on the flexural strength of Y-TZP dental ceramic. Journal of Dentistry. 2005;33(1):9-18. PMID: 15652163 DOI: http://dx.doi.org/10.1016/j.jdent.2004.07.001

8. Blue DS, Griggs JA, Woody RD, Miller BH. Effects of bur abrasive particle size and abutment composition on preparation of ceramic implant abutments. The Journal of Prosthetic Dentistry. 2003;90(3):247-254. PMID: 12942058 DOI: http:// dx.doi.org/10.1016/S0022-3913(03)00368-8

9. Sawase T, Wennerberg A, Hallgren C, Miyamoto I, Albrektsson T. Atomic force microscopic study of commercially available implant abutments. Clinical Implant Dentistry and Related Research. 1999;1(2):92-97. DOI: http://dx.doi.org/10.1111/j.1708-8208.1999. tb00097.x

10. Kawai Y, Uo M, Wang Y, Kono S, Ohnuki S, Watari F. Phase transformation of zirconia ceramics by hydrothermal degradation. Dental Materials Journal. 2011;30(3):286-292. DOI: http:// dx.doi.org/10.4012/dmj.2010-175

11. JCPDS - Joint Committee on Powder Diffraction Standards. Inorganic Materials. Swarthmore: International Centre for Diffraction Data; 1979.

12. Toraya H, Yoshimura M, Somiya S. Calibration curve for quantitative analysis of the monoclinic-tetragonal $\mathrm{ZrO} 2$ system by X-ray difraction. Journal of the American Ceramic Society. 1984;67(6):C-119-C-121. DOI: http://dx.doi. org/10.1111/j.1151-2916.1984.tb19715.x

13. Klug HP, Alexander LE. X-Ray Diffraction Procedures For Polycrystalline and Amourphous Materials. 2nd ed. New York: John Wiley; 1974. 